\title{
EFEKTIVITAS PERANGKAT PEMBELAJARAN BERBASIS KETERAMPILAN PROSES UNTUK MENINGKATKAN HASIL BELAJAR SAINS SISWA SEKOLAH DASAR
}

\author{
Liyana Sunanto \\ Universitas Pelita Bangsa \\ liyana.sunanto@pelitabangsa.ac.id
}

\begin{abstract}
This research is motivated by the problem of science learning outcomes caused by the use oflearning tools that have not stimulated process skills, causing less meaningful learning because students are not taught to find the concept but by rote. The purpose of this study was to determine the effectiveness of learning tools based on science process skills in improving science learning outcomes compared to students who only used learning tools at school. The research approach used is a quantitative approach with a quasi-experimental method with a pre-test and post-test control group design. The results showed that there was a significant difference in student learning outcomes using learning tools based on science process skills, the average score of science learning outcomes in the aspect of process skills in the pre-test and post-test experienced an increase in the average score of 22.98 greater compared to classes that use conventional learning tools, only an average score increase of 2.83 .
\end{abstract}

Keywords: learning kits; process skills; science learning outcomes

\begin{abstract}
Abstrak
Penelitian ini dilatar belakangi oleh adanya permasalahan hasil belajar sains yang disebabkan oleh penggunaan perangkat pembelajaran yang belum menstimulus keterampilan proses, menyebabkan pembelajaran yang kurang bermakna karena siswa tidak diajarkan menemukan konsepnya namun dengan hafalan. Adapun tujuan dari penelitian ini adalah untuk mengetahui efektivitas perangkat pembelajaran berbasis keterampilan proses sains dalam meningkatkan hasil belajar sains dibandingkan dengan siswa yang hanya menggunakan perangkat pembelajaran yang ada di sekolah. Pendekatan penelitian yang digunakan adalah pendekatan kuantitatif metode quasi experimental dengan desain pre test and post test control group design. Hasil penelitian menunjukan terdapat perbedaan yang siginifikan terhadap hasil belajar siswa dengan menggunakan perangkat pembelajaran berbasis keterampilan proses sains, skor rata-rata hasil belajar sains pada aspek keterampilan proses pada pre test dan post test mengalami peningkatan skor rata-rata sebesar 22,98 lebih besar dibandingkan kelas yang menggunakan perangkat pembelajaran konvensional hanya mengalami kenaikan skor rata-rata sebesar 2,83 .
\end{abstract}

Kata Kunci: hasil belajar sains; keterampilan proses; perangkat pembelajaran

\begin{tabular}{llll}
\hline Received & $: 2021-05-31$ & Approved & $: 2021-07-31$ \\
Reviesed & $: 2021-07-30$ & Published & $: 2021-07-31$ \\
\hline
\end{tabular}

\section{(c) (7) (2) Jurnal Cakrawala Pendas is licensed under a Creative Commons Attribution-}

ShareAlike 4.0 International License.

\section{Pendahuluan}

Ilmu Pengetahuan Alam (IPA) adalah pengetahuan yang rasional dan obyektif tentang alam semesta dengan segala isinya, selain itu IPA juga merupakan ilmu yang mempelajari peristiwa di alam. IPA perlu diajarkan pada jenjang sekolah dasar, dikarenakan termasuk dalam kurikulum suatu sekolah. Adapun alasan pentingnya IPA diajarkan di sekolah dasar yaitu (1) bermanfaat bagi bangsa, sebab IPA merupakan dasar teknologi sebagai pondasi pengetahuan dan pembangunan; (2) mata pelajaran yang menanamkan konsep berpikir kritis; (3) IPA 
merupakan pembelajaran keterampilan yang menyeluruh baik fisik maupun psikis, sehingga IPA bukanlah pelajaran hafalan; dan (4) IPA mengandung nilai dan potensi pendidikan yang membentuk kepribadian seseorang secara holistik (Mahpudin, 2018).

Rustaman, dkk menjelaskan bahwa sains merupakan produk, proses dan penerapannya dalam bentuk teknologi, termasuk juga sikap dan nilai-nilai yang terkandung di dalamnya (Rustaman, et al., 2015). Dengan demikian dapat dikatakan Ilmu Pengetahuan Alam (IPA) atau sains adalah sebuah bidang ilmu pengetahuan yang terdiri dari fakta, konsep, prinsip, hukum dan teori dimana kesemua aspek tersebut dapat dicapai dengan proses pembelajaran. Carin (1993) menjelaskan pengertian sains lebih terstruktur dan komprehensif, yaitu sains sebagai sebuah aktivitas dalam menjawab dan mengeksplor alam semesta dan menemukan sesuatu yang belum diketahui. Ada lima poin penting dalam menjelaskan sains, yakni: order and organizing, observation, interpretation, tentativeness, and modeling. Kelima hal tersebut merupakan hal yang terkandung dalam sains itu sendiri. Alat standarisasi peringkat sains biasa dilakukan oleh PISA dan TIMSS, dimana mereka melakukan survey terhadap anak usia sekolah dengan memberikan soal yang harus siswa pecahkan.

Belajar dan pembelajaran sains merupakan (1) pendeskripsian dan penggambaran bermacam interaksi pembelajaran dalam kelas, (2) mendemonstrasikan dan mencontohkan dengan bahasa pembelajaran sains dasar di kelas, dan (3) menunjukan bagaimana ide dapat digunakan untuk menunjukkan pengembangan profesional guru sains (Mortimer \& Scott, 2003). Untuk mengoptimalkan pembelajaran sains tersebut dapat diupayakan melalui lima ranah dalam a new "taxonomy for science education" yang dikembangkan oleh Allan J MacCormack dan R.E. Yager meliputi: (1) ranah pengetahuan, (2) ranah proses sains, (3) ranah kreativitas, (4) ranah sikap/atitude, dan (5) ranah aplikasi dan koneksi (Prasida, 2016). Kelima ranah taksonomi pendidikan sains dapat dilihat pada Gambar 1. Pengembangan taksonomi melihat bahwa kelima ranah penting dalam membantu siswa membebaskan diri dari buta sains yang diperlukan untuk hidup bermasyarakat, contohnya kelima ranah ini diperlukan dalam menyelesaikan masalah yang dihadapi agar menjadi kehidupan kelak yang lebih baik.

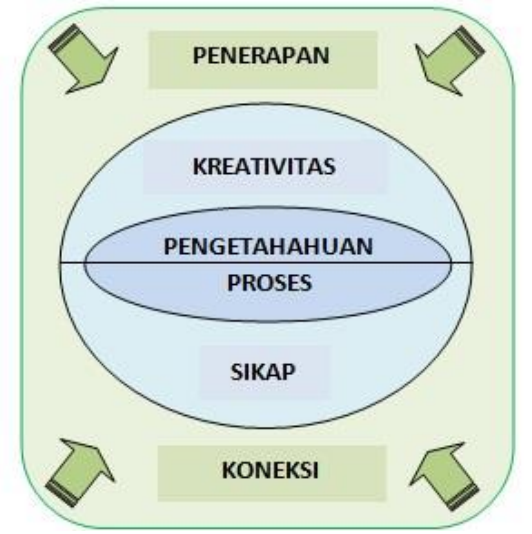

Gambar 1. Lima Domain dalam Pembelajaran Sains

Proses pembelajaran sains siswa dituntut untuk aktif dari awal pembelajaran sampai akhir pembelajaran yaitu menyimpulkan apa yang ia peroleh selama mengikuti pembelajaran sains. Penguasaan sains melalui pembelajaran secara teoritis ditentukan oleh kemampuan dan kreativitas siswa dalam menguasai keterampilan proses sains. Untuk itulah maka dipandang perlunya suatu perangkat pembelajaran berbasis keterampilan proses guna meningkatkan hasil belajar sains siswa. Perlunya guru dalam mendesain pembelajaran yang baik yang ditunjang dengan pemilihan metode yang tepat sesuai dengan karakter materi. Guru sains yang efektif 
menggunakan metode pembelajaran yang bervariasi yang disesuaikan dengan materi yang akan disampaikan, selain itu guru juga harus selalu menerapkan dalam pemikirannya tentang Apa yang akan saya sampaikan dalam mengajar? Dan Bagaimana caranya agar saya dapat menyampaikan materi tersebut dengan baik? (Gejda \& LaRocco, 2006).

Abdurrahman secara umum menjelaskan hasil belajar merupakan kemampuan yang diperoleh anak setelah melalui kegiatan belajar. Menurutnya anak yang berhasil dalam belajar ialah yang berhasil mencapai tujuan pembelajaran atau tujuan instruksional (Abdurrahman, 1999). Sejalan dengan pendapat sebelumnya, Supratiknya pun mengemukakan bahwa hasil belajar yang menjadi objek penilaian kelas berupa kemampuan-kemapuan baru yang diperoleh siswa setelah mereka mengikuti proses belajar-mengajar tentang mata pelajaran tertentu (Widodo \& Widayanti, 2013). Rumusan tujuan pendidikan pada sistem pendidikan nasional mengacu pada klasifikasi belajar dari Bloom, yaitu aspek kognitif, afektif dan psikomotor.

Apabila siswa hanya terbiasa menjawab pertanyaan guru, maka perlu dirubah menjadi bertanya kepada guru maupun siswa yang lain. Lalu siswa yang biasanya hanya mencatat halhal yang disampaikan guru, perlu dirubah menjadi membuat peta konsep atau merangkum. Serta dari siswa yang hanya mendengarkan ceramah guru menjadi mempresentasikan apa yang dipelajarinya Kegiatan ini dapat merubah kualitas belajar siswa dari surface learning menjadi deep learning. Dengan demikian siswa merubah kebiasaan awal yang terbiasa menghafal konsep-konsep sains menjadi menguasai konsep-konsep sains, yang selanjutnya berkembang menjadi menguasai keterampilan sains. Adapun ciri-ciri proses pembelajaran yang inovatif adalah menyenangkan, menantang, aktif, kreatif, mandiri, interaktif dan inspiratif sehingga dapat meningkatkan hasil belajar sains melalui keterampilan proses (Igboegwu \& Egbutu, 2011). Keterampilan proses sains perlu dikembangkan melalui pengalaman langsung yang melibatkan penggunaan berbagai material dan tindakan fisik (Amining, Slamet, \& Dewi, 2015).

Keterampilan proses sains merupakan keterampilan dasar yang memfasilitasi pembelajaran dalam ilmu sains, membuat siswa aktif, memupuk rasa tanggung jawab, meningkatkan pembelajaran dan metode penelitian. Sehingga dapat dikatakan keterampilan proses sains adalah keterampilan yang dimiliki seseorang dalam menggunakan pikiran, nalar serta perbuatan secara efisien dan efektif untuk mencapai suatu hasil (Gurses, Cetinkaya, Dogar, \& Sahin, 2015). Aydogdu, dkk menjelaskan keterampilan proses sains merupakan salah satu keterampilan berpikir yang paling sering digunakan (Kurniawan \& Fadloli, 2016), sama halnya yang disampaikan Rillero menjelaskan siswa yang tidak memahami penggunaan keterampilan proses sain akan mengalami kesulitan dalam kehidupan sehari-hari, dikarenakan keterampilan proses sains dapat digunakan dalam kehidupan sehari-hari, bukan hanya digunakan selama pembelajaran (Aydogdu, Erkol, \& Erten, 2014).

Keterampilan proses adalah keterampilan khusus yang mempermudah belajar ilmu pengetahuan, mengaktifkan siswa mengembangkan rasa tanggung jawab siswa dalam belajar, meningkatkan pemahaman materi pembelajaran yang lebih permanen, serta mengajari siswa metode penelitian (Karamustafaoglu, 2011). Keterampilan proses juga penting untuk membuat pembelajaran lebih bermakna, karena belajar berlangsung sepanjang hayat, dan individu perlu menemukan, menafsirkan dan menilai bukti-bukti dalam kondisi yang berbeda yang mereka hadapi. Sejalan dengan pendapat tersebut Subagyo, Wiyanto dan Marwoto menjelaskan pembelajaran dengan pendekatan keterampilan proses memungkinkan siswa dapat menumbuhkan sikap ilmiah untuk mengembangkan keterampilan yang mendasar, sehingga dalam proses pembelajaran siswa dapat memahami konsep yang dipelajarinya (Subagyo, Wiyanto, \& Marwoto, 2009). Dengan demikian hasil belajar sains yang meliputi pengetahuan, 
keterampilan dan sikap sebagai tuntutan kompetensi dalam kurikulum yang dikembangkan saat ini dapat tercapai. Selain itu, keterampilan proses sains juga dapat meningkatkan pemahaman persepsi siswa tentang keterampilan kuantitatif mereka (Setiawan \& Sugiyanto, 2020).

Peringkat PISA Indonesia dari 79 negara Tahun 2018 turun dibanding Tahun 2015. Kemampuan membaca memperoleh skor 371 (peringkat 74) sebelumnya 397, kemampuan membaca memperoleh skor 379 (peingkat 73) sebelumnya 386 dan kemampuan kinerja sains memperoleh skor 396 (peringkat 71) sebelumya 403 (Tohir, 2019). Berdasarkan data PISA tahun 2018 tersebut, anak Indonesia masih rendah dalam kemampuan kinerja sains. Indonesia untuk pertama kalinya mengikuti survey empat tahunan yang diadakan oleh TIMSS (Trends in Inetrnational Mathematics and Science Study) pada Tahun 2015 dalam menilai kemampuan sains siswa Sekolah Dasar (SD), tepatnya siswa kelas IV SD dimana selama ini yang diikutkan adalah siswa kelas VIII.

Berkaca dari hasil PISA dan TIMSS, maka peningkatan kualitas pembelajaran menjadi hal yang penting agar dapat meningkatkan kemampuan siswa dalam pembelajaran. Guru sekolah dasar perlu melakukan inovasi dalam pembelajarannya khususnya pembelajaran IPA atau sains agar dapat membelajarkan sains semaksimal mungkin kepada siswa. Untuk itu guru dituntut mengembangkan perangkat pembelajaran sains pada mata pelajaran sains. Cara pengemasan pengalaman belajar yang dirancang guru berpengaruh besar terhadap kebermaknaan pengalaman bagi siswa.

Pada kenyataannya, masih ada guru yang kurang kreatif dalam melakukan inovasi dalam pembalajaran IPA. Hal ini terlihat dari penggunaan secara utuh perangkat pembelajaran dari salah satu penerbit tanpa terlebih dahulu disesuaikan dengan karakteristik siswanya dan lingkungan belajar yang mendukung. Sehingga banyak siswa yang memandang IPA sebagai mata pelajaran yang membosankan karena materi yang disajikan oleh guru tidak memberikan pengalaman yang bermakna, ditandai dengan siswa masih sering dituntut untuk menghafalkan materi dan teori. Data yang diperoleh dalam studi pendahuluan untuk mengetahui keadaan awal siswa di sekolah menunjukan hasil belajar IPA pada materi "Daur Air" masih tergolong rendah, hal ini terlihat dari nilai rata-rata hasil belajar siswa sebesar $70(\mathrm{KKM}=72)$ dengan nilai rata-rata aspek keterampilan prosesnya adalah $61 \%$.

Permasalahan di atas perlu segera diatasi dengan tepat, salah satu caranya yakni dengan menyesuaikan perangkat pembelajaran yang sesuai dengan kebutuhan serta karakteristik belajar IPA dan karakteristik siswa. Dari hasil observasi lapangan pun didapat bahwa guru kurang kreatif dan inovatif dalam mengembangkan perangkat pembelajaran yang sesuai dengan karakteristik pembelajaran IPA dan karakteristik siswa. Siswa pada kelas V lebih menyukai pembelajaran yang menyenangkan dan bermakna yang tidak menekankan pada hafalan saja, selain itu dapat mengakomodir kemampuan kolaborasi dan komunikasinya. Keterampilan proses sains yang rendah disebabkan oleh beberapa faktor, diantaranya pembelajaran yang hanya menekankan penguasaan konsep, serta kegiatan pembelajaran yang belum mengekplorasi keterampilan proses siswa (Sukarno, Anna, \& Ida, 2013). Analisis hasil observasi disimpulkan bahwa sumber permasalahan hasil belajar yang rendah disebabkan oleh penggunaan perangkat pembelajaran belum mengakomodir keterampilan proses sains yang berpengaruh terhadap hasil belajar. Sehingga diperlukan perangkat pembelajaran yang mampu meningkatkan hasil belajar siswa dengan menggunakan perangkat pembelajaran berbasis keterampilan proses. 


\section{Metode Penelitian}

Pendekatan penelitian yang digunakan adalah pendekatan kuantitatif metode quasi experimental dengan desain pre test and post test control group design, penentuan sampel dari penelitian ini tidak dilakukan secara acak, kedua kelompok diberi tes awal, diberi perlakuan, dan kemudian diberikan tes akhir (Creswell, 2012). Eksperimen pada penelitian ini adalah untuk mengetahui efektivitas perangkat pembelajaran berbasis keterampilan proses terhadap hasil belajar sains siswa kelas V Sekolah Dasar. Populasi dalam penelitian ini adalah siswa kelas V SDN Klangenan III Tahun Ajaran 2019/2020 yang memiliki dua rombel dengan jumlah masing-masing siswa di tiap kelasnya yang dijadikan sampel penelitian adalah 31 siswa. Alasan dipilihnya sekolah tersebut berdasarkan hasil observasi awal dan wawancara, diantaranya adalah siswa kelas V mengalami kesulitan meningkatkan hasil belajar pada mata pelajaran sains.

Teknik pengambilan sampel penelitian yang digunakan adalah purposive sampling, yaitu teknik pengambilan sampel dengan pertimbangan dan kriteria khusus (memiliki hasil belajar yang homogen) dari data yang representatif (Haidar, Yuliati, \& Handayanto, 2020). Sampel penelitian diperoleh dari dua rombel kelas dengan memenuhi kriteria hasil belajar sains yang homogen, data yang digunakan dalam uji homogenitas adalah data UTS siswa kelas. Penentuan kelas eksperiman dan kelas kontrol pada penelitian ini dilakukan secara acak setelah dilakukan uji homogenitas.

Data pada penelitian ini menggunakan data kuantitatif. Adapun data tersebut diperoleh melalui observasi/pengamatan dan tes. Lembar pengamatan digunakan untuk mengamati sikap ilmiah yang muncul saat pembelajaran. Tes yang digunakan ada dua macam, yaitu pre test dan post test. Pada awal proses pembelajaran siswa di kelas eksperimen maupun kelas kontrol diberikan tes awal (pre test) dengan menggunakan instrumen soal uraian. Pada kelas eksperimen penggunaan perangkat pembelajaran sains berbasis keterampilan proses, sedangkan pada kelas kontrol proses pembelajaran menggunakan perangkat pembelajaran konvensional dengan metode konvensional yaitu ceramah dan tanya jawab.

Data yang akan dibandingkan dalam penelitian ini adalah nilai hasil belajar sains yang menggunakan perangkat pembelajaran berbasis keterampilan proses dengan hasil belajar sains siswa yang menggunakan perangkat pembelajaran konvensional. Data yang diperoleh melalui instrumen penilaian dianalisis dengan menggunakan statistik deskriptif, yang kemudian analisis ini digunakan untuk menggambarkan karakteristik pada masing-masing variabel.

\section{Hasil dan Pembahasan}

Hasil penelitian ini adalah nilai rata-rata hasil belajar siswa pada mata pelajaran IPA sebelum dan sesudah pembelajaran dengan menggunakan perangkat pembelajaran berbasis keterampilan proses. Data yang didapat dianalisis secara deskriptif yang menggambarkan perolehan rata-rata hasil belajar siswa pada mata pelajaran IPA yang dapat dilihat pada Gambar 2. Hasil belajar pada kelas yang menggunakan perangkat pembelajaran sains berbasis kerteampilan proses diperoleh data skor rata-rata pre test 62,42 dan post test 85,40 , mengalami kenaikan 22,98. Pada kelas kontrol proses pembelajaran menggunakan perangkat yang ada di sekolah diperoleh skor rata-rata pre test 61,44 , post test 64,47 , mengalami kenaikan 2,83 . Bila dibandingkan antara kelas eksperimen dan kelas kontrol keduanya mengalami kenaikan skor dan nilai pre test - post test . kenaikan skor dan nilai pada kelas eksperimen lebih tinggi dari kelas kontrol. 


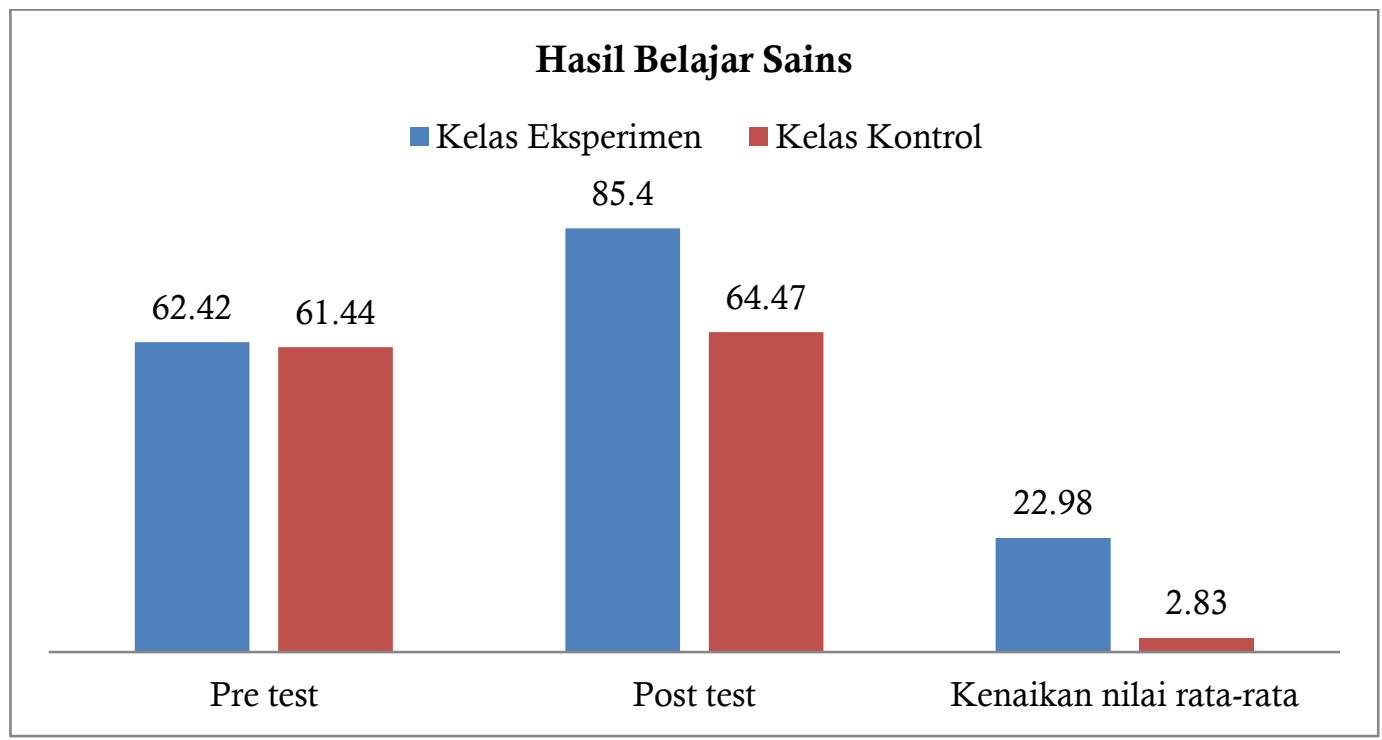

Gambar 2. Diagram Nilai Rata-rata Hasil Belajar Sains

Pengujian hipotesis dilakukan pada perbedaan hasil belajar siswa kelas eksperimen yang menggunakan perangkat pembelajaran berbasis keterampilan proses dan kelas kontrol. Hal ini dikarenakan hasil belajar mempertimbangkan aspek kemampuan awal siswa. Selain itu data dari masing-masing kelas pada aspek hasil belajar menjamin data yang diperoleh murni berasal dari perlakuan, dan tidak berasal dari perlakuan sebelum eksperimen. Secara singkat, hasil perhitungan independent sample t test untuk kedua kelompok ditinjau dari hasil belajar kognitif siswa pada masing-masing kelas dapat dilihat pada Tabel 1.

Tabel 1. Ringkasan Uji Perbedaan Hasil Belajar

\begin{tabular}{llllllll}
\hline Kelas & Rerata Skor & $\mathbf{N}$ & $\mathbf{d f}$ & $\mathbf{t}_{\text {hitung }}$ & $\mathbf{t}_{\text {tabel }}$ & $\mathbf{p}$ & Keterangan \\
\hline $\mathbf{K E}$ & 23,06 & 1 & 60 & 2,536 & 2,000 & 0,014 & $\mathrm{H}_{0}$ ditolak \\
$\mathbf{K K}$ & 17,35 & 31 & & & & & \\
\hline
\end{tabular}

Tabel 1 memperlihatkan bahwa harga $t_{\text {hitung }}$ adalah 2,536 dengan tingkat signifikansi 0,014 . Karena $t_{\text {hitung }}>t_{\text {tabel }}$ atau harga signifikansi lebih kecil daripada 0,05 , maka $\mathrm{H}_{0}$ ditolak. Berdasarkan hal tersebut maka dapat disimpulkan bahwa terdapat perbedaan yang signifikan pada hasil belajar antara kelas yang menggunakan perangkat pembelajaran sains berbasis keterampilan proses dengan kelas yang menggunakan perangkat pembelajaran yang ada di sekolah.

Berdasarkan data di atas, pembelajaran IPA dengan menggunakan perangkat pembelajaran berbasis keterampilan proses dapat meningkatkan hasil belajar sains siswa. Hasil ini sesuai dengan pendapat (Aktamis \& Ergin, 2008) menjelaskan bahwa menemukan sesuatu dalam penelitian yang dilakukan oleh siswa dengan keterampilan proses dapat meningkatkan kreativitas ilmiah siswa, sikap siswa terhadap sains, dan hasil belajar sains.

\section{Kesimpulan}

Penggunaan perangkat pembelajaran berbasis keterampilan proses efektif dalam meningkatkan hasil belajar sains siswa kelas V sekolah dasar. Adapun nilai rata-rata hasil belajar siswa pada kelas eksperimen yang menggunakan perangkat pembelajaran berbasis keterampilan proses mengalami kenaikan yang cukup signifikan dibandingkan dengan kelas 
kontrol yang menggunakan perangkat pembelajaran yang tersedia disekolah hanya mengalami sedikit peningkatan, sehingga perbandingan nilai rata-rata hasik belajar sains pada kelas eksperimen lebih tinggi dibanding kelas kontrol.

\section{Daftar Pustaka}

Aktamis, H., \& Ergin, O. (2008). The Effect of Scientific Process Skills Education in Student's Scientific Creativity, Science attitudes and Academic Achievements. Journal of AsiaPacific Forum on Science Learning and Teaching, 1-21.

Amining, R., Slamet, S., \& Dewi, P. S. (2015). Improving Student's Science Proces Skill in Biology Through. Seminar Nasional XII Pendidikan Biologi FKIP UNS (hal. 428-433). Solo: UNS.

Aydogdu, B., Erkol, M., \& Erten, N. (2014). The investigation of science process skills of elementary. Journal of Asia-Pacific Forum on Science Learning and teaching, 1-28.

Carin, \& Sund. (1981). Teaching Modern Science. New York: Macmillan.

Creswell, J. W. (2012). Educational Research: Planning, Conducting, and Evaluating Quantitative and Qualitative Research - 4th Edition. Boston: pearson Education.

Gejda, L. M., \& LaRocco, D. J. (2006). Inquiry-based Instruction in Secondary Classroom: A Survey of Teacher Practice. The 37th Annual Northeast Educational Research Association Conference (hal. 1-34). Kerhonkson: NY.

Gurses, A., Cetinkaya, S., Dogar, C., \& Sahin, E. (2015). Determination of Levels of Use of Basic Process Skills of High School Students. Journal of Procedia - Social and Behavioral Science, 644-650.

Haidar, D. A., Yuliati, L., \& Handayanto, S. K. (2020). The Effect of Inquiry Learning with Scaffolding on Misconception of Light Material among Fourth-Grade Students. Jurnal Pendidikan IPA Indonesia, 540-553.

Igboegwu, E., \& Egbutu, R. (2011). Effects of Cooperative Learning Strategy and Demonstration. Journal of Research and Development, Volume 3 No 1 December 2011, 1-10.

Karamustafaoglu, S. (2011). Improving the Science Process Skills Ability of Science Student Teachers Using I Diagrams. Eurasian Journal of Physics and Chemistry Education, 26-38.

Kurniawan, A., \& Fadloli. (2016). Profil Penguasaan Keterampilan Proses Sains Mahasiswa. Seminar Nasional XIII Pendidikan Biologi FKIP UNS (hal. 410-419). Surakarta: Biology Education Departement Fakulty of Teacher Training and Education UNS.

Mahpudin. (2018). Peningkatan Hasil Belajar IPA melalui Metode Eksperimen pada Siswa Kelas V Sekolah Dasar. Jurnal Cakrawala Pendas, 1-8.

Mortimer, E. F., \& Scott, P. H. (2003). Meaning Making in Secondary Science Classroom. Philadelpia: Open University Press.

Prasida. (2016). International Education \& Research Journal (IERJ), 132-134.

Rustaman, N., Nono, S., Ucu, R., Anna, R., Titi, W., Sandra, S. A., et al. (2015). Materi dan Pembelajaran IPA SD. Tangerang Selatan: Universitas Terbuka.

Setiawan, A. M., \& Sugiyanto. (2020). Science Process Skills Analysis of Science Teacher on Professional Teacher Program in Indonesia. Jurnal Pendidikan IPA Indonesia, 241-247.

Subagyo, Y., Wiyanto, \& Marwoto, P. (2009). Pembelajaran dengan Pendekatan Keterampilan Proses untuk Meningkatkan Penguasan Konsep Suhu dan Pemuaian. Jurnal Pendidikan Fisika Indonesia, 42-46.

Sukarno, Anna, P., \& Ida, H. (2013). The Profile of Science Process Skill (SPS) Student. International Journal of Scientific Engineering and Research (IJSER), 79-83.

Tohir, M. (2019). Hasil PISA Indonesia Tahun 2018 Turun Dibanding Tahun 2015. Dipetik Mei 24, 2021, dari Researchgate: https://www.researchgate.net/publication/337717927_Hasil_PISA_Indonesia_Tahun_2 018_Turun_Dibanding_Tahun_2015 